\title{
Bovine zoonoses in Cameroon's West region: Knowledge, attitudes, and practices of herdsmen
}

\author{
Kouengoua Kouengoua Armelle Prudence ${ }^{1}$ (D), Nankam Chimi Roland ${ }^{1}$,, Oyetola Wilfried Délé2(iD, \\ Njayou Ngapagna Arouna ${ }^{1}$ (D), Alambedji Rianatou Bada² (i) and Jean-Pierre Vaillancourt ${ }^{3}$ (D)
}

\begin{abstract}
1. Department of Pathology and Reproduction, Université des Montagnes, Bangangté, Cameroon; 2. Department of Microbiology, Immunology and Infectious Diseases, Ecole Inter-Etats des Sciences de Médecine Vétérinaire, Dakar, Senegal; 3. Swine and Poultry Infectious Disease Research Center, Faculty of Veterinary Medicine, Université de Montréal, Montreal, Canada.

Corresponding author: Kouengoua Kouengoua Armelle Prudence, e-mail: kouenpru@yahoo.com

Co-authors: NCR: nankamroland_2@yahoo.fr, OWD: oyetolaw@yahoo.fr, NNA: anjayoungapagna@gmail.com, ARB: rianatoub@yahoo.fr, JV: jean-pierre.vaillancourt@umontreal.ca

Received: 31-05-2021, Accepted: 14-09-2021, Published online: 06-12-2021
\end{abstract}

doi: www.doi.org/10.14202/IJOH.2021.227-231 How to cite this article: Prudence KKA, Roland NC, Délé OW, Arouna NN, Bada AR, Vaillancourt J (2021) Bovine zoonoses in Cameroon's West region: Knowledge, attitudes, and practices of shepherds, Int J One Health, 7(2):227-231.

\begin{abstract}
Background and Aim: Shepherds are in constant contact with animals, and they are potential hosts for the transmission of zoonoses. This study aimed to assess the perceptions of shepherds in Cameroon's West region regarding zoonotic diseases.

Materials and Methods: A cross-sectional study was conducted from August to October 2017, on 218 shepherds. The data were collected using semi-structured interviewer-administered questionnaires. The participants were assessed on their knowledge, attitudes, and practices that might expose them to bovine zoonose transmission, and the data were analyzed with $\mathrm{R}$, version 2.13.0. Descriptive statistics were generated, and the association between socio-demographic characteristics and knowledge was explored using the Chi-square test.

Results: Out of the 218 herdsmen, (205/218) 94\% did not have any education, and (195/218) 89.5\% did not know the definition of zoonosis. There was a correlation between the level of education and knowledge of the definition of zoonosis: About (162/218) 74.6\% cited tuberculosis as a zoonosis, (62/218) $28.4 \%$ said the main modes of transmission were by ingestion of contaminated milk, and (66/218) 30.3\% by consumption of contaminated meat. Abortions during the third trimester of gestation, combined with the presence of hygroma, were described by (130/218) $59.6 \%$ of the participants as brucellosis symptoms. In terms of practices and attitudes, (187/218) 85.8\% and (50.14/218) 23.0\% of the participants confirmed that they consumed raw milk and raw meat, respectively. Almost all (214/218) 98.1\% interviewees stated that blood consumption is forbidden. In case of suspicion of disease, (204/218) 93.6\% maintained that they treated sick animals without a veterinary prescription, and (209/218) 95.9\% left the carcasses in the wild. After contact with animals, (181/218) $83.3 \%$ washed their hands. Finally, (192/218) 88.3\% would like to be informed about zoonoses.
\end{abstract}

Conclusion: The level of knowledge about zoonotic diseases was low; a high percentage of shepherds followed inadequate hygiene practices and expressed concern about zoonoses. As a result, they are at risk of exposure to pathogens. It would be in the interest of public health to develop training programs for shepherds and livestock owners to mitigate zoonotic risks.

Keywords: knowledge, attitudes, and practices survey, shepherds, West region of Cameroon, zoonoses.

\section{Introduction}

Zoonoses are defined as "diseases or infections naturally transmissible from vertebrate animals to humans and vice versa" [1]. The emergence and re-emergence of zoonotic infections, and their potentially disastrous impact on human health, are causing growing concern worldwide [2], and this should favor a close collaboration between animal health and public health authorities to address the issue [3]. Brucellosis, rabies, trypanosomiasis, bovine tuberculosis, cysticercosis, echinococcosis, and anthrax are listed as seven

Copyright: Prudence, et al. This article is an open access article distributed under the terms of the Creative Commons Attribution 4.0 International License (http://creativecommons.org/licenses/ by/4.0/), which permits unrestricted use, distribution, and reproduction in any medium, provided you give appropriate credit to the original author(s) and the source, provide a link to the Creative Commons license, and indicate if changes were made. The Creative Commons Public Domain Dedication waiver (http:// creativecommons.org/ publicdomain/zero/1.0/) applies to the data made available in this article, unless otherwise stated. endemic zoonoses of global concern [4]. Third world countries are more affected by infectious and communicable diseases, most of which are zoonotic and have destructive social and economic effects [5].

In Cameroon, cattle farming is an intense activity. The cattle herd is estimated at about 5 million heads, and the most practiced farming system is extensive farming [6], which promotes close and prolonged contact between humans and their cattle. These contacts increase the risk of exposure to zoonoses [6]. Cameroon's West region, despite its relatively low population compared to the rest of the country, constitutes an interesting study area. In recent years, the livestock sector has grown significantly in Cameroon's West region [6]. A number of recent studies conducted in Cameroon; on avian influenza by Feussom[7] in the West Region, on rabies by Centre Pasteur[8] in the Central Region, on tuberculosis in abattoirs located in western areas, 
by Awah [9], on brucellosis by Bayang [10] in the North Region, and on anthrax by UN-OCHA [11] in the Northwest Region show that the occurrence of zoonoses should be a national concern. Nevertheless, there is very limited information on the knowledge, attitudes, and practices (KAP) of shepherds, who are mostly exposed to zoonoses transmitted by cattle in Cameroon's West region. Yet, their involvement is essential to successfully control and manage the spread of these diseases.

This study was undertaken to assess the shepherds' knowledge of zoonoses transmitted by cattle and to identify their attitudes and practices in regard to the adoption of measures to prevent and combat them.

\section{Materials and Methods}

\section{Ethical approval and informed consent}

Ethical approval was obtained from the ethical review committee of Université des Montagnes, Bangangté (2017/195/UdM/PR/CIE). The consent was obtained from all respondents before the commencement of data collection.

\section{Study period and location}

The study was conducted from August to October 2017 in the west region of Cameroon; at the cattle markets in Bamboutos, Menoua, Ndé, and Noun. They are open for business for 1 or 2 days a week. The west region of Cameroon is experiencing strong livestock growth made up of species such as zebu (peulh, white fulani, red fulani, goudali, and others).

\section{Study design and participants}

A descriptive cross-sectional survey was employed in this study. A preliminary questionnaire was tested on ten participants. The study participants were shepherds from Cameroon's West region. All consenting participants were included in the study, and individuals who were not from this region were excluded from the study.

\section{Sample size determination}

The minimum size was calculated using the Charan and Biswas formula for descriptive studies [12]: $n=t^{2}$ $\mathrm{x} \mathrm{p}(1-\mathrm{p}) / \mathrm{m}^{2}$

Where $\mathrm{n}$ is the minimum sample size needed,

- $\mathrm{m}$ is the level of error that can be tolerated (0.05 chance of error)

- $\mathrm{p}$ is the proportion we assumed would answer yes to the question concerning the knowledge on zoonoses. It was set arbitrarily at $50 \%$.

- $\quad \mathrm{t}$ is the standard normal deviation corresponding to a $95 \%$ confidence level.

At $95 \%$ level confidence level, $\mathrm{t}=1.96$

$\mathrm{n}=1.96^{2} \times 0.5(1-0.5) / 0.05^{2}$

$\mathrm{n}=3.8416 \times 0.5 \times 0.5 / 0.0025$

$\mathrm{n}=384.16$

The minimum sample size was rounded up to 384 .

\section{Data collection}

Convenience sampling was conducted using a semi-structured interviewer-administered questionnaire. The interview was mainly conducted in "Foulbé" (local language), with the help of an interpreter, followed by French and "Pidgin English" (a mixture of English and other languages, which allows communication among people who do not share a common language). The interviewees were questioned on their KAP toward zoonoses. A total of 218 shepherds were interviewed (instead of 384, as previously planned), due to time constraints imposed by cattle market operations. The questionnaire is available on request to the corresponding author.

\section{Statistical analysis}

The data collected were entered in Sphinx, plus $^{2}$ software version 5.1.0 (Sphinx, France), exported to Microsoft Excel (Microsoft Corporation, USA), and analyzed in R, version 2.13.0. (R Foundation, Vienna, Austria). The proportions of each response modality were obtained by taking as denominator the number of respondents for each question. This number varied because some questions were not answered by all interviewees. The descriptive results were summarized using frequency tables and charts. The association between socio-demographic characteristics and knowledge was assessed using the Chi-square test at a $5 \%$ significance level[13].

\section{Results}

Respondents were mainly male, with a low level of education. Specifically, 94\% of the interviewed shepherds had no education. Overall, the following numbers of interviewees did not answer questions related to: mode of transmission, 142; treatment, 151; blood consumption, 2; and hand sanitation, 1.

\section{Shepherds' knowledge of zoonoses transmitted by cattle}

Before specifically asking questions about zoonoses, a general question was posed about which diseases the shepherds normally encountered. The diseases cited were parasitic infections due to ticks ( $24.3 \%$ of respondents), followed by foot-and-mouth disease $(21.9 \%)$ which is more encountered in the Noun Division and contagious bovine peripneumonia $(19.2 \%)$, more reported in the Ndé Division. The vast majority of shepherds $(89.5 \%)$ did not know the definition of zoonosis (Table-1). It is noteworthy that $94 \%$ of shepherds did not have any education. A significant difference was observed between the interviewees' educational level and knowledge of the definition of zoonosis $(\mathrm{p}=0.03)$. Majority of shepherds $(74.6 \%)$ mentioned tuberculosis (identified by the caseous nodules found in lymphatic nodes); $26.8 \%$ mentioned fascioliasis, described by the presence of a common liver fluke found in the liver after the animals have been slaughtered; $2.8 \%$ mentioned brucellosis when speaking of abortion cases with swollen knees; and $1.4 \%$ of shepherds cited anthrax without describing any symptom. The best known modes of transmission of zoonoses were: Consumption of contaminated meat 
Table-1: Distribution of the educational level of shepherds according to knowledge about the definition of a zoonosis.

\begin{tabular}{lccc}
\hline Educational level & Yes & No & Believe does not exist \\
\hline Highest degree of education obtained & $19^{\mathrm{a}}(8.7)^{\mathrm{b}}$ & $195(89.5)$ & $4(1.8)$ \\
None & $16(7.3)$ & $185(84.9)$ & $4(1.8)$ \\
Coranic school & $0(0.0)$ & $6(2.8)$ & $0(0.0)$ \\
Elementary & $3(1.4)$ & $3(1.4)$ & $0(0.0)$ \\
Secondary & $0(0.0)$ & $0(0.0)$ & $0(0.0)$ \\
University & $0(0.0)$ & $1(0.5)$ & $0(0.0)$ \\
\hline
\end{tabular}

${ }^{\mathrm{a}}$ Number of participants, ${ }^{\mathrm{b}}$ Percentage of participants

(30.3\%), followed by ingestion of contaminated milk (28.4\%); contact with excretions and secretions of sick animals (11.5\%); and direct contact with sick animals $(10.1 \%)$. Almost $60 \%$ of the shepherds reported abortions during the third trimester of gestation associated with hygromas, called "Bakhalé" meaning brucellosis in local language, which would indicate the presence of brucellosis.

\section{Attitudes and practices of shepherds in terms of zoo- nosis prevention and treatment}

From this study, it emerged that the vast majority of shepherds (93.6\%) treat sick animals using veterinary drugs bought at the livestock market without a prescription, $75.7 \%$ sell them before treatment, $19.7 \%$ slaughter them, and $4.1 \%$ quarantine the animals. Most shepherds (95.9\%) leave dead animals in the wild; $37.1 \%$ bury them, while $10.6 \%$ consume their meat. Milk is consumed either raw or cooked. A greater proportion of shepherds (55.3\%) prefer to drink raw milk, while the rest (44.7\%) pasteurize it before drinking. Meat is also consumed either cooked or raw. Specifically, $77.0 \%$ and $23.0 \%$ of shepherds reported consuming cooked $(38.4 \%$ boiled; $37.5 \%$ roasted; and $1.10 \%$ dried) and raw meat, respectively. Almost all shepherds (98.1\%) indicated that the consumption of blood is prohibited. To the question: "Do you wash your hands after being in contact with animals?" $83.5 \%$ of the respondents confirmed that they always wash their hands, $7.8 \%$ said that they often wash them but not always, and $8.7 \%$ stated that they do not wash their hands at all. Only $7.8 \%$ of shepherds had some knowledge of zoonoses, mainly on tuberculosis. The majority $(88.3 \%)$ showed an interest in receiving information on zoonoses.

\section{Discussion}

\section{Shepherds' knowledge of zoonoses transmitted by} cattle

From the KAP survey on zoonoses conducted among shepherds in Cameroon's Western Region, it emerges that most shepherds do not know what zoonosis is. On the other hand, in Senegal, a little more than a quarter $(30.1 \%)$ of the participants in the same survey knew, or had heard of, the term zoonosis [14]. The lack of knowledge regarding zoonotic diseases may be explained by the low level of education reported among shepherds. This is in contrast with research results reported in the Punjab region, India, where $77.6 \%$ of breeders possessed a primary, secondary or higher level of education [15]. As shepherds are known to be frequently in contact with livestock, it is necessary to raise their awareness, and to provide them with educational opportunities regarding zoonotic diseases and their control. The importance of education is emphasized by the fact that a significant correlation was recorded between the level of education and the likelihood that shepherds knew the definition of zoonosis. However, despite the fact that shepherds are generally not educated, some have empirical knowledge of zoonoses, mainly of tuberculosis and, to a lesser extent, of fascioliasis, brucellosis, and anthrax. These are the most widespread diseases in the region; tuberculosis and fascioliases, in particular, are frequently detected in slaughterhouses. The ingestion of contaminated milk, as well as the consumption of contaminated meat, are known as risky practices, as they are modes of transmission of zoonoses. In India, $55.6 \%$ and $67.2 \%$ of shepherds mentioned the consumption of contaminated milk and meat, respectively [15]. These percentages are considerably higher than those recorded in the present study, highlighting again the need for proper education and training to raise awareness about zoonoses. Farmers possess a significant body of knowledge, in their own local language, about the clinical signs associated with these pathogens. As part of a surveillance program, the comprehensive understanding of local expressions could play an important role in the detection of suspected diseases. A study in India revealed that $47.2 \%$ of the surveyed farmers were aware of the fact that animals can abort during the third trimester of gestation because of brucellosis [15]. It was observed that the percentage of shepherds with similar knowledge was higher in surveyed areas in Senegal. The fact that shepherds have such knowledge concerning brucellosis, and can describe its clinical signs, will facilitate the control and management of this disease.

\section{Attitudes and practices of shepherds in terms of zoo- nosis prevention and treatment}

Sick animals are generally treated without the advice of a veterinarian, and shepherds mostly buy drugs from the cattle markets without any prescription. This situation points to the urgency of controlling the use of veterinary drugs, raising farmers' awareness of the disadvantages of treating animals without veterinary prescription and about the development of antimicrobial resistance, as well as to the need of involving 
veterinarians in the assistance of pastoral activities. In the event of death, $95.9 \%$ of shepherds leave the carcasses in the wild. This practice could be explained by the fact that in the "Mbororo" culture, it is forbidden to touch the carcass of a dead animal, as it is considered a potential source of germs that could then be spread [16]. In contrast, in Turkey, for example, $22.5 \%$ of shepherds dispose of the carcasses of animals that died from disease by burying them deep into the ground [17]. Both the practices of burying the carcasses and leaving them out in the wild are risky due to the possible persistence of pathogens in the environment and contamination of groundwater. Consumption of (raw) milk is a common practice in Senegal [14], where it was reported that $95 \%$ of the farmers drank fresh milk without prior heat treatment. The consumption of fresh milk is preferred because heating alters its taste. This indicates that globally, in Africa, the consumption of raw or fresh milk is a risky practice, and farmers are aware of it. In terms of meat consumption, most shepherds were reported to eat cooked meat. However, even if only a minority of them eats very limited amounts of uncooked meat, this is still a risk that must be addressed by public health officials. Consumption of blood is prohibited by cultural law, says $98.1 \%$ of herdsmen. Although in Tanzania [18], it was reported that $43 \%$ of producers consume raw blood. Such practice is considered risky because of possible disease transmission. For example, consumption of raw pig products, including blood, is associated with trichinellosis and Streptococcus suis meningitis infections in humans [19]. In relation to hand washing after contact with animals, $83.5 \%$ of farmers reported always washing their hands, against the $7.8 \%$ who washed them occasionally during milking. In Turkey, [17] it was reported that $91.4 \%$ of shepherds wash their hands after being in contact with animals. Although the percentage of respondents who confirmed washing their hands is high, it is important to consider that in studies on the prevalence of handwashing conducted in public settings, over-reporting of compliance to this hygiene practice is often observed [20]. Following our results in Cameroon on awareness of zoonosis, $<10 \%$ of the shepherds said that they had already been made aware at least once about such disease by a local veterinarian, or by the competent authorities during vaccination campaigns, or at slaughterhouses. On the other hand, more than half of the shepherds were simply not aware of zoonoses. Although a majority $(88.3 \%)$ of the surveyed shepherds declared their interest in learning more about zoonoses, a minority remained reluctant because, according to them, the results of surveys in which they had participated before have never been forwarded to them.

\section{Limitation of the study}

It should be noted that the present study has some limitations. Our sampling focused only on four divisions (Noun, Ndé, Bamboutos, and Menoua) instead of all the eight that constitute Cameroon's West region because in these four, more cattle are present and livestock markets are functional. Although it was not possible to interview as many shepherds as desired, we believe that the scale of the survey still provides an overview of the target population. There was likely almost no selection bias because, as farming areas are difficult to access, all cattle farmers move around in search of greener pastures and then travel to the cattle markets. Furthermore, all shepherds contacted during our investigation agreed to participate.

\section{Conclusion}

To raise shepherds' awareness on bovine zoonoses is important in preventing and combating disease transmission because shepherds are in contact with animals and other people, they may contribute to environmental contamination. A One Health Community approach is required to control zoonosis transmission. Campaigns for the education and training of shepherds should be organized frequently to increase the knowledge and modify the perception of these stakeholders regarding zoonoses. This achievement is essential to promote and establish better hygienic practices in the field.

\section{Authors' Contributions}

JV, ARB, NNA, and KKAP: Conceptualized and designed the study. KKAP: Data collection. KKAP and NCR: Data analysis. KKAP, OWD, and JV: Review of data for critical intellectual content. All authors read and approved the final manuscript.

\section{Acknowledgments}

The authors are grateful to the shepherds, MINEPIA staff of the West region, Cameroon for their cooperation, and the Veterinary school of Dakar (EISMV), Senegal. The authors are grateful to One Health Central and Eastern Africa for financing this study.

\section{Competing Interests}

The authors declare that they have no competing interests.

\section{Publisher's Note}

Veterinary World (Publisher of International Journal of One Health) remains neutral with regard to jurisdictional claims in published institutional affiliation.

\section{References}

1. Joubert, L. (2018) Zoonoses Encyclopædia Universalis. Available from: http://www.universalis.fr/encyclopedie/ zoonoses. Retrieved on 06-03-2018.

2. Woolhouse, M. and Sonya, E.J.S. (2005) Host range and emerging and re-emerging pathogens. Emerg. Infect. Dis., 11(12): 1842-1847.

3. Chardon, H. and Brugere, R. (2017) Zoonoses au plan mondial, enjeux et perspectives. $V P C, 33(4)$ : 1-9.

4. World Health Organization. (2006) The Control of Neglected 
Zoonotic Diseases: A Route to Poverty Alleviation. Report of a Joint WHO/DFID-AHP Meeting with the Participation of FAO and OIE, Geneva. Available from: https://www.apps. who.int/iris/handle/10665/43485. Retrieved on 06-03-2018.

5. Singh, B.B., Sharma., Gundai, J.P.S., Aulakh, R.S., Banga, H.S. (2011) Climate change, zoonoses and India. Rev. Sci. Tech., 30(3): 779-788.

6. Cameroun. Ministère de L'élevage des Pêches et Industries Animales. (2014) Annuaire des Statistiques du Sous-secteur Elevage, Pêche et Industries Animales. Rapport EPIA STAT, Yaoundén. p89. Available from: https://www.ins-cameroun.cm/wp-content/uploads/2014/02/0CHAPITRE-14_ PECHE-ET-ELEVAGE.pdf. Retrieved on 07-03-2017.

7. Feussom, J.M. (2016) Expérience du Pays Maladies des Animaux Terrestres Cameroun. Available from: http:// www.rr-africa.oie.int/docspdf/fr/2016/WAHIS/cameroun Jour2 Groupe 3.pdf. Retrieved on 1-10-2017.

8. Centre Pasteur du Cameroun. (2012) Rapport D'activités. Available from: http://www.pasteur-yaounde.org/files/ rapport_2012_centre_pasteur_cameroun_V2.pdf.(CPC). Retrieved on 12-03-2018.

9. Awah, J.N., Caleb, A.K., Bradley, G., Ane-Anyangwe, I.N., Fon-Tebug, S. and Tchoumboue, J. (2010) Prevalence of bovine tuberculosis in abattoirs of the littoral and western highland regions of Cameroon: A cause for public health concern. Vet. Med. Int., 57(2): 59-76.

10. Bayang, H.N. (2014) Prévalence et Facteurs de Risque de la Brucellose Dans le Grand Nord et Dans la Région de L'Adamaoua (Cameroun), Thèse. Médecine Vétérinaire Ngaoundéré, Cameroon. p86.

11. UN-OCHA. (2017) Anthrax-bovine. Available from: https:// www.humanitarianresponse.info/.../cameroon/.../cameroun-épizootie-danthrax bovine. Retrieved on 4-07-2017.

12. Charan, J. and Biswas, T. (2013) How to calculate sample size for different study designs in medical research. Indian.
J. Psychol. Med., 35(2): 121.

13. Cochran, W.G. (1952) The chi-square test of goodness of fit. Ann. Math. Stat., 23(3): 315-345.

14. Tebug, S.F., Kamga, W.A.R., Ema, P.J., Muyeneza, C., Kane, O., Seck, A., Ly, M.T. and Lo, M. (2015) Cattle farmer awareness and behavior regarding prevention of zoonotic disease transmission in Senegal. J. Agromedicine, 20(2): 217-224.

15. Jaspal, S., Simrinder, S., Aparna, G., Jaswinder, S. and Udeybir, S. (2016) Awareness, knowledge, and risks of zoonotic diseases among livestock farmers in Punjab. Vet. World, 9(2): 186-191.

16. NSW Department of Primary Industries. (2018) Animal Carcass Disposal. Available from: https://www.dpi.nsw. gov.au/emergencies/emergency/management/resources-and-publications. Retrieved on 10-09-2017.

17. Hülya, Ç., Leyla, A., Esra, K. and Mustafa, A. (2015) Evaluation of farmers' knowledge-attitude-practice about zoonotic diseases in Kars Turkey. Kafkas. J. Med. Sci., 5(3): 87-93.

18. Swai, S., Luuk, S. and Daborn, C.J. (2010) Knowledge and attitude towards zoonoses among animal health workers and livestock keepers in Arusha and Tanga, Tanzania. Tanz. J. Health Res., 12(4): 282-288.

19. Walter, R.J.T., Giang, V.T., Thai, Q.N., Duong, V.D., Viet, K.N., Cap, T.N., Lam, T.N., Chinh, Q.L., Teresa, S., Thi, C.T.D., Thi, H.N.T., Thang, D.N., Khoung, T.P., Annette, F., Peter, H., Heiman, W., Hanh, N.D., Hong, H.N., Lien, M.T.T., Trung, V.N., Kinh, V.N. and Duc, H.N. (2009) Acute febrile myalgia in Vietnam due to trichinellosis following the consumption of raw pork. Clin. Infect. Dis., 49(7):79-83.

20. Nurul, A.M., Nur, N.Z.A., Ramli, S., Isahak, I. and Salleh, N.M. (2016) Knowledge, attitudes and practices of hand hygiene among parents of preschool children. J. Sci. Innov. Res., 5(1): 1-6. 